\title{
Intra-Axonal Transport and Turnover of Neurophysins in the Rat
}

\section{A PROPOSAL FOR A POSSIBLE ORIGIN OF THE MINOR NEUROPHYSIN COMPONENT}

\author{
By GRAHAM D. BURFORD and BRIAN T. PICKERING \\ Department of Anatomy, The Medical School, University of Bristol, University Walk, \\ Bristol BS8 1TD, U.K.
}

(Received 23 July 1973)

\begin{abstract}
1. Radioactivity associated with the three neurophysins in the neural lobe of the rat was determined at intervals up to 5 weeks after an intracisternal injection of $\left[{ }^{35}\right.$ S $]$ cysteine. 2 . The radioactivity associated with the two major neurophysins (one supposedly associated with vasopressin and the other with oxytocin) increased linearly for $12 \mathrm{~h}$ after the injection and the ratio of the rates of increase in the two proteins was very similar to the ratio of vasopressin to oxytocin in the gland. 3 . From $12 \mathrm{~h}$ onwards the radioactivity associated with each major neurophysin declined exponentially but the half-life of the supposed oxytocin-neurophysin (13.3 days) was shorter than that for the supposed vasopressinneurophysin (19.8 days). 4. The kinetics of labelling of the minor neurophysin was quite different from that of the two major ones. It became slowly labelled during 3-5 days after injection and the radioactivity hardly decreased during the following 4 weeks. 5 . The data could support the hypothesis that the minor neurophysin is a metabolic product of oxytocin-neurophysin. The exponential rate of disappearance of radioactivity from oxytocin-neurophysin and the minor component taken together has a rate constant similar to that for vasopressin-neurophysin (e.g. half-life $=18.9$ days).
\end{abstract}

Since the discovery (van Dyke et al., 1942) that the hormones oxytocin and vasopressin could be extracted in the form of an active complex ('van Dyke protein') with an inert protein, there has been much speculation on the possible physiological role of this protein, which was named neurophysin (Acher et al., 1955). An early suggestion (for review see Ginsburg, 1968) was that neurophysin was a carrier protein that kept the hormones within neurosecretory granules during transport from their sites of synthesis in the hypothalamus, and during storage in the neural lobe. More recently, a close biosynthetic relationship between protein and hormones has been suggested (for reviews, see Sachs et al., 1969; Pickering et al., 1971) as several studies, particularly the pulse-chase experiments of Sachs et al. (1971), are compatible with neurophysin being part of the precursor protein that Sachs \& Takabatake (1964) proposed as an early intermediate in the biosynthesis of vasopressin. When the hormones are finally released from the gland it now seems clear that the neurophysins are released along with them (Fawcett et al., 1968; Sachs, 1971; Uttenthal et al., 1971; McNeilly et al., 1972), and this is compatible with the suggestion (Douglas et al., 1971) that release occurs by exocytosis of the entire contents of the neurosecretory granules.

Posterior pituitary glands from cattle (Rauch et al., 1969) and pigs (Uttenthal \& Hope, 1970; Burford et al., 1971a; Coy \& Wuu, 1971) were shown to contain two major and one minor neurophysin component(s).
The neurophysins of other species, which have not been studied as extensively, have also been found to occur in multiple forms (Cheng \& Friesen, 1972; Watkins, 1971, 1972a). During differential centrifugation of bovine neurohypophyses one of the major neurophysins (neurophysin-I) tended to sediment with oxytocin, and the other (neurophysin-II) with vasopressin (Dean et al., 1968). Moreover, by the use of specific antisera, Robinson et al., (1971) showed that the plasma concentration of neurophysin-I in cows increased in situations known to be associated with the release of oxytocin, whereas plasma neurophysin-II increased during vasopressin-related phenomena. Thus it would appear that, at least in cattle, oxytocin and vasopressin are associated with separate neurophysins. Similar findings have recently been reported (Pickup et al., 1973) for the porcine neurophysins, although in this species it is the neurophysin with the higher electrophoretic mobility (neurophysin-I) that is associated with vasopressin.

We have shown (Burford et al., 1971b) that the rat also elaborates two major and one minor neurophysin(s). One of the major components (neurophysin-A), which is absent from rats with hereditary diabetes insipidus (Brattleboro strain), has been associated with vasopressin and the other (neurophysin B) with oxytocin. Preliminary experiments on the hypothalamus (Burford et al., 1972a) have shown that the supraoptic nucleus synthesizes relatively more neurophysin-A (vasopressin-neurophysin) than 
neurophysin-B, whereas the converse is true for the paraventricular nucleus. A number of other workers (Norström \& Sjöstrand, 1971a; Norström et al., 1971; Coy \& Wuu, 1972; Watkins, 1972b) were unable to resolve the two major rat neurophysins, but this was probably due to insufficient concentrations of Bromophenol Blue used as a tracking dye during polyacrylamide-gel electrophoresis (Burford \& Pickering, 1972).

Norström \& Sjöstrand (1971b) followed the change in radioactivity of their unresolved mixture of the major rat neurophysins after injection of $\left[{ }^{35} \mathrm{~S}\right]-$ cysteine into the hypothalamus. We now report the turnover of each separate component and suggest a possible explanation for the occurrence of the minor neurophysin component.

A preliminary communication of some of this work has been made (Burford et al., 1972b).

\section{Experimental}

\section{Materials}

Animals. Male rats (180-220g) were used from the departmental colony of Wistar animals (Porton strain derived M.R.C. Carshalton).
Radioactive cysteine. $\mathrm{L}-\left[{ }^{35} \mathrm{~S}\right]$ Cysteine hydrochloride (SJ-141) of specific radioactivity $32-46 \mathrm{mCi} / \mathrm{mmol}$ was obtained from The Radiochemical Centre, Amersham, Bucks., U.K. and was diluted to $1 \mathrm{mCi} / \mathrm{ml}$ before use.

\section{Methods}

Intracisternal injections. Rats were anaesthetized with halothane and given subarachnoid injections of $50 \mu \mathrm{Ci}$ of $\left[{ }^{35} \mathrm{~S}\right]$ cysteine by the intracisternal route as described by Pickering \& Jones (1971).

Polyacrylamide-gel electrophoresis. Rat neurallobes were homogenized individually in $0.05 \mathrm{ml}$ of $0.1 \mathrm{M}$ $\mathrm{HCl}$ and left at $4^{\circ} \mathrm{C}$ for $18 \mathrm{~h}$. Tris $(1 \mathrm{mg})$ was added to the homogenate and any precipitate that formed, together with the unextracted residue, was removed by centrifugation. The supernatant was then layered on a polyacrylamide gel for electrophoresis by the modification of the method of Davis (1964) described previously (Burford et al., 1971b; Burford \& Pickering, 1972).

Determination of radioactivity. Gels were sliced after staining, and the radioactivity of each slice $(1.1 \mathrm{~mm})$ was determined as described previously

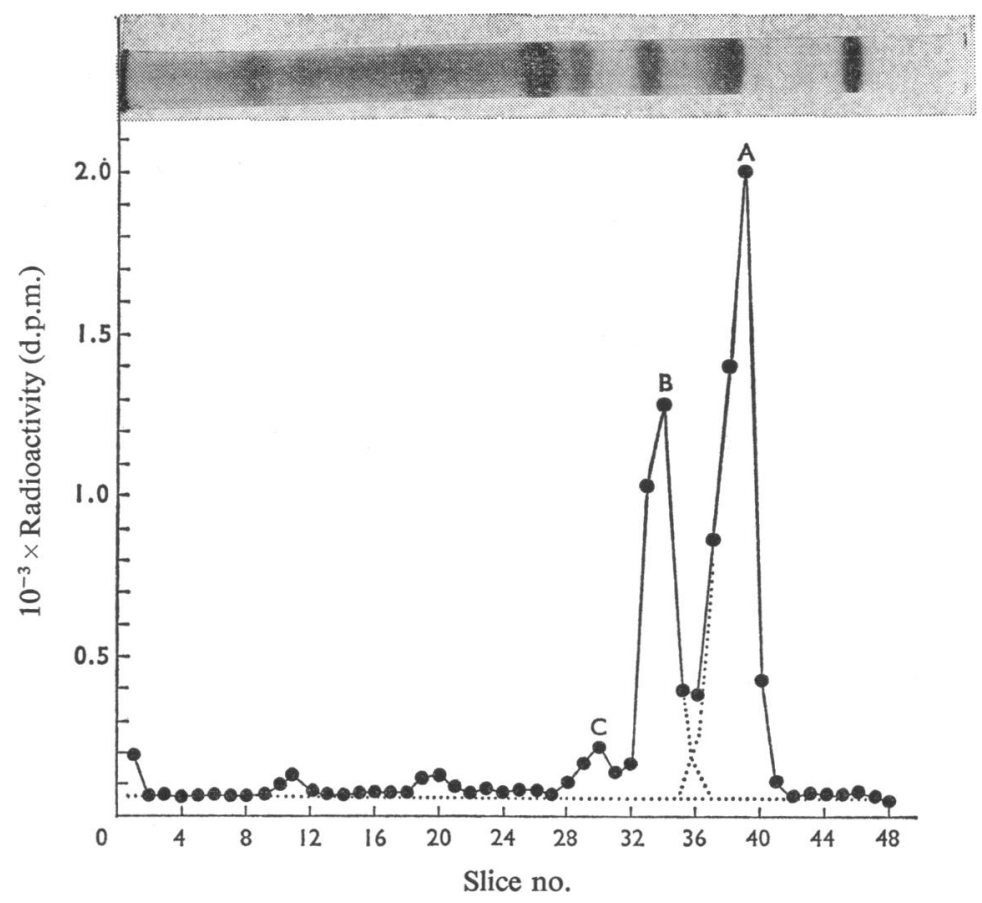

Fig. 1. Distribution of radioactivity in a polyacrylamide gel after electrophoresis of an extract of rat neural lobe

The rat had received an intracisternal injection of $50 \mu \mathrm{Ci}$ of $\left[{ }^{35} \mathrm{~S}\right]$ cysteine $24 \mathrm{~h}$ before death. The neural lobe was extracted and fractionated as described in the text. 
(Burford et al., 1971b). Correction was made for radioactive decay so that results were expressed as d.p.m./slice on the day of injection (i.e. when the injected dose had a radioactivity of $50 \mu \mathrm{Ci}$ ). The distribution of radioactivity was then plotted and the total amount of radioactivity in each protein determined from this graph after extrapolation as shown in Fig. 1.

\section{Results}

\section{Increase in the radioactivity of the neurophysin}

Polyacrylamide-gel electrophoresis of an acidic extract of a rat neural lobe $24 \mathrm{~h}$ after an intracisternal injection of $\left[{ }^{35}\right.$ S $]$ cysteine, showed that more than $80 \%$ of the radioactivity recovered from the gel was always associated with the three neurophysins (Fig. 1). The possibility that an appreciable amount of this radioactivity represented extraneous $\left[{ }^{35} \mathrm{~S}\right]$ cysteine bound to the proteins by disulphide links is ruled out by the observation (Norström et al., 1971) that, during electrophoresis in the presence of sodium dodecyl sulphate after reduction with 2-mercaptoethanol, the radioactivity moved with a protein of molecular weight about 12000; all disulphide bonds would be broken under these conditions.

When neural lobes were studied at various times, radioactivity was first found to be associated with the major neurophysins $2 \mathrm{~h}$ after injection of the label. Thereafter the protein fractions became progressively

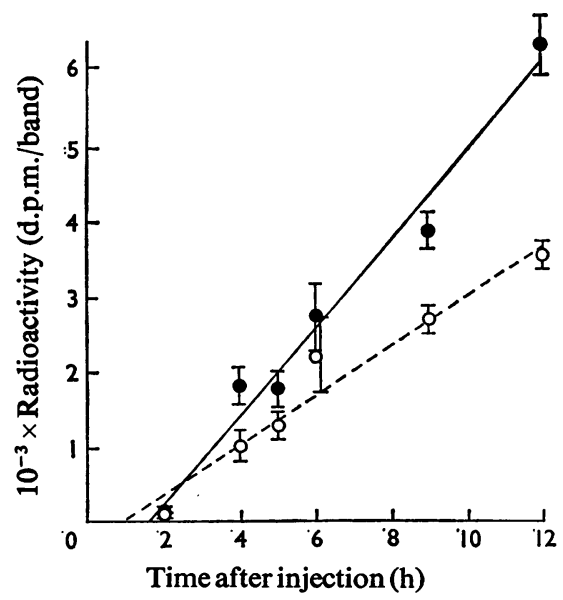

Fig. 2. Increase of radioactivity in the major neurophysins of the rat neural lobe at various times after an intracisternal injection of $50 \mu \mathrm{Ci}$ of $\left[{ }^{35} S\right]$ cysteine

$\bullet$, Neurophysin-A (vasopressin-neurophysin); $\circ$, neurophysin-B (oxytocin-neurophysin). Vertical bars show the S.E.M. for four or five determinations. more radioactive, the value reaching a maximum after approximately $12-16 \mathrm{~h}$. This initial increase in radioactivity appeared to be linear with time (Fig. 2) and the lines of best fit gave highly significant $(P<0.001)$ correlation coefficients: $r_{\mathrm{A}}=0.95, n=24 ; r_{\mathrm{B}}=0.91$, $n=24$.

The minor neurophysin, $\mathrm{C}$, did not appear to become labelled until 4-5h after the injection and it gradually increased in radioactivity for 3-5 days.

Disappearance of radioactivity from the neurophysin fractions

Although maximum labelling of the major neurophysins occurred 12-16h after injection of the radioisotope, the glandular proteins were still radioactive 5 weeks later (Table 1). The slow decline in the radioactivity of the proteins seemed to be exponential and the logarithms of the radioactivity showed a highly significant linear regression over the period from $12 \mathrm{~h}$ to 5 weeks (Fig. 3). The lines plotted in Fig. 3 were calculated by the least-squares method and were fitted by the expressions:

and

$$
\log N_{\mathrm{A}}=3.73-6.33 \times 10^{-4} t
$$

$$
\log N_{\mathrm{B}}=3.55-9.40 \times 10^{-4} t
$$

where $N_{\mathrm{A}}$ and $N_{\mathrm{B}}$ are the radioactivities (d.p.m./ gland) of the respective neurophysins and $t$ is the time (h) after injection. Each of the lines had highly significant $(P<0.001)$ correlation coefficients $\left(r_{\mathrm{A}}=-0.82\right.$, $\left.n=79 ; r_{\mathrm{B}}=-0.88, n=79\right)$ and the slopes of the two regression lines were significantly different $(P<0.005)$

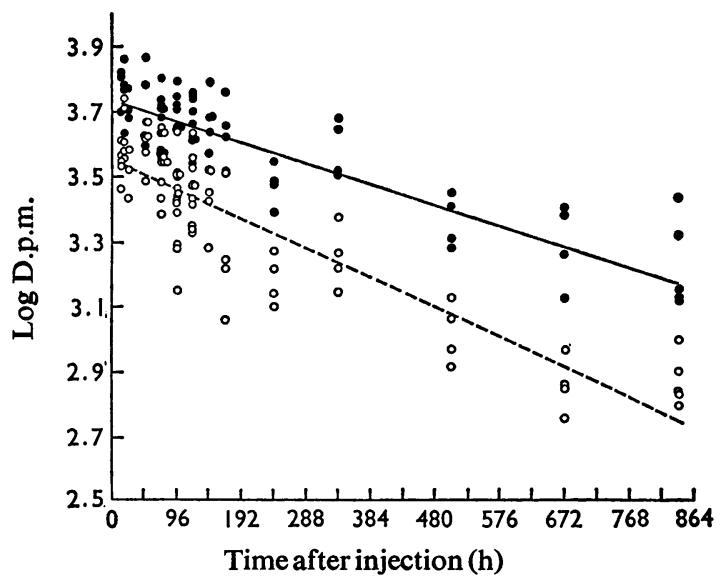

Fig. 3. Decline in radioactivity associated with the two major rat neurophysins at various times after an intracisternal injection of $\left[{ }^{35} S\right]$ cysteine

$\bullet$, Neurophysin-A; 0 , neurophysin-B. 
Table 1. Radioactivity associated with each of the rat neurophysins at various times after an intracisternal injection of $50 \mu C i$ of $\left[{ }^{35} S\right]$ cysteine

A and $B$ are the major neurophysins tentatively associated with vasopressin and oxytocin respectively (Burford et al., 1971b), and C is the minor neurophysin component.

Radioactivity (d.p.m./gland) in each neurophysin (mean \pm S.E.M.)

\begin{tabular}{|c|c|c|c|c|}
\hline & & & & \\
\hline (h) & determinations & $\mathbf{A}$ & B & $\mathrm{C}$ \\
\hline 1 & 4 & $\mathbf{0}$ & $\mathbf{0}$ & 0 \\
\hline 2 & 3 & $155 \pm 4$ & $124 \pm 22$ & 0 \\
\hline 4 & 4 & $1811 \pm 249$ & $1016 \pm 204$ & $117 \pm 81$ \\
\hline 5 & 4 & $1763 \pm 254$ & $1275 \pm 179$ & $65 \pm 25$ \\
\hline 6 & 4 & $2731 \pm 464$ & $2197 \pm 487$ & $233 \pm 105$ \\
\hline 9 & 4 & $3864 \pm 253$ & $2681 \pm 187$ & $124 \pm 22$ \\
\hline 12 & 5 & $6313 \pm 382$ & $3515 \pm 189$ & $386 \pm 26$ \\
\hline 16 & 5 & $5977 \pm 483$ & $4374+373$ & $416+80$ \\
\hline 24 & 4 & $4563 \pm 720$ & $3016 \pm 350$ & $477 \pm 122$ \\
\hline 48 & 5 & $5232 \pm 634$ & $3977 \pm 270$ & $1086 \pm 239$ \\
\hline 72 & 10 & $4727 \pm 275$ & $3501 \pm 219$ & $1486 \pm 230$ \\
\hline 96 & 11 & $4598 \pm 335$ & $2691 \pm 239$ & $833 \pm 80$ \\
\hline 120 & 10 & $4540 \pm 292$ & $2900 \pm 219$ & $1284 \pm 77$ \\
\hline 144 & 5 & $4691 \pm 442$ & $2817 \pm 260$ & $1495 \pm 177$ \\
\hline 168 & 4 & $3853 \pm 726$ & $1951 \pm 456$ & $1014 \pm 318$ \\
\hline 240 & 4 & $3035 \pm 224$ & $1539 \pm 135$ & $1058 \pm 166$ \\
\hline 336 & 4 & $3919 \pm 399$ & $1817 \pm 210$ & $1637+170$ \\
\hline 504 & 4 & $2355 \pm 224$ & $1065 \pm 116$ & $1032 \pm 82$ \\
\hline 672 & 4 & $2046 \pm 281$ & $736 \pm 73$ & $703 \pm 128$ \\
\hline 840 & 5 & $1800 \pm 278$ & $761 \pm 63$ & $957+99$ \\
\hline
\end{tabular}

and gave half-times for disappearance of radioactive neurophysin of 19.8 days and 13.3 days for neurophysin A and B respectively.

All of the above results applied only to the major neurophysins (A and $B$ ). The minor component (C), which, as mentioned above, continued to increase in radioactivity up to 3-5 days, remained close to this maximum for most of the 5 -week period studied.

\section{Discussion}

After an intracisternal injection of $\left[{ }^{35}\right.$ S $]$ cysteine, the pattern of labelling of both of the major neurophysins in the neural lobe of the rat pituitary closely paralleled that previously shown (Jones \& Pickering, 1972) for oxytocin and vasopressin by using $\left[{ }^{3} \mathrm{H}\right]-$ tyrosine. Radioactivity began to be associated with the proteins between 1 and $2 \mathrm{~h}$ after injection of the label, reached peak rates after $12-16 \mathrm{~h}$ and slowly declined during the following 5 weeks.

During the first $12 \mathrm{~h}$, the radioactivity increased linearly with time. The rates of increase of radioactivity of the two proteins were significantly different $(P<0.001)$ giving further evidence that they are indeed separate entities. As both proteins began to be labelled at about the same time (i.e. 1-2h after injection), it may be assumed that they are transported along the axons with similar velocities and thus the difference between the two rates of increase may be assumed to reflect a difference in the rates of biosynthesis of the two proteins. In this context it is interesting that the ratio (1.79) of the slopes of the lines plotted in Fig. 2 is not very different from the vasopressin/oxytocin ratio $(1.50 \pm 0.06)$ for this strain of rat (Jones \& Pickering, 1969).

A further indication that neurophysins-A and -B were really separate proteins was given by the significant difference in the rates at which their radioactivity declined. However, the half-time for the disappearance of radioactivity from protein A (19.8 days) agreed well with the value of about 19 days for the unresolved mixture of the major rat neurophysins, calculated from the results of Norström \& Sjöstrand (1971b). Because we considered that neurophysin-A is related to vasopressin and neurophysin-B to oxytocin (Burford et al., 1971b), and also because radioactive oxytocin and vasopressin disappear from rat glands at similar rates (Jones \& Pickering, 1972), the finding that the radioactivity of the two major neurophysins declined at different rates was unexpected and is discussed further below. 
Norström \& Sjöstrand (1971b) interpreted their results as suggesting that there was a fast and a slow rate of transport of neurophysin from the hypothalamus to the neural lobe. Our present results do not support this contention: there were no fluctuations in the disappearance curves that could not be ascribed to experimental variation, even though we increased the number of experiments at the crucial time-intervals of 3-5 days after injection.

The time-course for the labelling of the minor neurophysin $(C)$ bore no resemblance to that of the major components. As has already been shown by Norström \& Sjöstrand (1971b), this minor radioactive constituent continued to increase in radioactivity for 3-5 days. One of the reasons that led us to suggest that each of the major neurophysins was associated with a separate hormone was the observation that the ratio (radioactivity in neurophysin-A)/(radioactivity in neurophysin-B) was the same as the ratio vasopressin/oxytocin in these glands (Burford et al., 1971b). As the time-course proceeded, however, it became apparent that this relationship held only for up to $24 \mathrm{~h}$ after injection; in glands examined after this the radioactivity ratio gradually increased. It occurred to us that this divergence of the two ratios began at the time when the labelling of neurophysin-C first became appreciable, suggesting that $C$ might be a metabolic product of neurophysin $B$. If this were so, neurophysins-B and $-C$ should be considered together. When the decline of the sum of the radioactivities in these two neurophysins was analysed a $\log$-linear regression line $\left(\log N_{\mathrm{B}+\mathrm{C}}=3.65-6.02 \times\right.$ $\left.10^{-4} t\right)$ resulted with a highly significant $(P<0.001)$ correlation coefficient $(r=-0.77, n=79)$ and with a slope not significantly different from that for neurophysin-A (e.g. $t_{\ddagger}=18.9$ days) (Fig. 4). The ratio

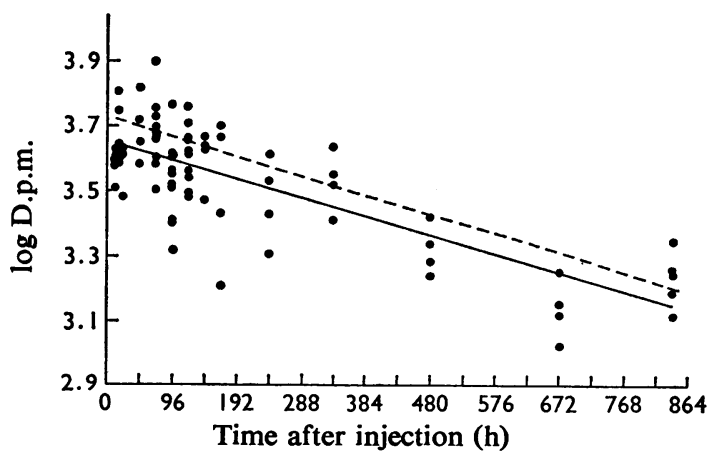

Fig. 4. Decline of the total radioactivity associated with both neurophysin- $B$ and neurophysin- $C$

For comparison, the broken line shows the decline of neurophysin-A radioactivity (from Fig. 3). Sum of radioactivity for neurophysin-B and -C. (radioactivity in neurophysin- $\mathrm{A}$ )/(radioactivity in neurophysins $B+C$ ) was similar to the vasopressin/ oxytocin ratio at all times. Moreover, if the line plotted for the increase of radioactivity in neurophysin-B (Fig. 2) is corrected for the small contribution from $\mathrm{C}$, the ratio of the slopes for the increase of radioactivity in the two proteins (i.e. their relative rates of synthesis) becomes 1.63. It therefore seems that, at least in the rat, the minor neurophysin (C) may arise from the oxytocin-neurophysin after the latter has arrived in the neural lobe. If, as seems reasonable to assume, this conversion is effected enzymically (since all three neurophysins can be sedimented in neurosecretory granules; R. W. Swann \& B. T. Pickering, unpublished work), the enzyme responsible must also occur within these granules. There is an increasing amount of evidence that the neurohypophysial hormones may be formed from their precursor protein during the transport of the neurosecretory granules from the perikarya in the hypothalamus to the nerve termini in the neural lobe (Sachs et al., 1969; Pickering et al., 1971), and this conversion would also require a proteinase within the granule. We have no evidence to suggest that neurophysin-A is similarly degraded and it would appear that either it does not possess the sensitive bond present in neurophysin-B or that a metabolic product analogous to $C$ is not resolved from $A$ under our separation conditions. D. B. Hope and his colleagues (Pickup et al., 1973) have recently obtained evidence which could be interpreted to suggest that in the pig some of the vasopressin may be associated with neurophysin-III instead of with neurophysin-I. If one were to interpret their results in this way, it might be suggested that porcine neurophysin-III is derived from porcine neurophysin-I.

The half-times (about 19 days) calculated for the disappearance of the radioactive neurophysins ( $A$ and $B+C)$ from the neural lobe are different from those determined by Jones \& Pickering (1972) for oxytocin and vasopressin (about 13 days). The half-life of the hormones was very similar to that found for neurophysin-B, which we are proposing is artificially short because of the partial transformation of $B$ into $C$. At first sight this would suggest either that the hormones are eliminated more rapidly than the neurophysins, or that we should be attempting to explain a slower decline in the radioactivity of band $\mathrm{A}$ rather than a faster one of band B. However, as pointed out by Jones \& Pickering (1972), the hormone values, relying on multiple bioassays, would not be expected to be as precise as those obtained from a study of the neurophysins. Indeed, the slope of the regression line for neurophysin-A (Fig. 3) was not significantly different from those for oxytocin and vasopressin (Fig. 2, Jones \& Pickering, 1972). Thus it would appear that the neurophysins and hormones are eliminated at similar rates as well as arriving in the gland at similar 
rates. This is in accord with a close association of the proteins from the time of synthesis to the time of release.

We are pleased to acknowledge the assistance of Mrs. Janet Mallam and Miss Hazel Beaver. The work was supported in part by grants from The Royal Society and the Medical Research Council.

\section{References}

Acher, R., Manoussos, G. \& Olivry, G. (1955) Biochim. Biophys. Acta 16, 155-156

Burford, G. D. \& Pickering, B. T. (1972) Biochem. J. 128 , 941-944

Burford, G. D., Ginsburg, M. \& Thomas, P. J. (1971a) Biochim. Biophys. Acta 229, 730-738

Burford, G. D., Jones, C. W. \& Pickering, B. T. (1971b) Biochem. J. 124, 809-813

Burford, G. D., Dyball, R. E. J., Moss, R. L. \& Pickering, B. T. (1972a) J. Physiol. (London) 222, 156-157

Burford, G. D., Sacks, S. H. \& Pickering, B. T. (1972b) Proc. Int. Congr. Endocrinol. 4th Abstr. 115

Cheng, K. W. \& Friesen, H. G. (1972) J. Clin. Endocrinol. Metab. 34, 165-176

Coy, D. H. \& Wuu, T. C. (1971) Anal. Biochem. 44, 174181

Coy, D. H. \& Wuu, T. C. (1972) Biochim. Biophys. Acta 263, 125-132

Davis, B. J. (1964) Ann. N.Y. Acad. Sci. 121, 404-427

Dean, C. R., Hope, D. B. \& Kazic, T. (1968) Brit. J. Pharmacol. 34, 192P

Douglas, W. W., Nagasawa, J. \& Schulz, R. (1971) Mem. Soc. Endocrinol. 19, 353-378

Fawcett, C. P., Powell, A. \& Sachs, H. (1968) Endocrino$\log y$ 83, 1299-1310

Ginsburg, M. (1968) Handb. Exp. Pharmacol. 23, 286-371
Jones, C. W. \& Pickering, B. T. (1969) J. Physiol. (London) 203, 449-458

Jones, C. W. \& Pickering, B. T. (1972) J. Physiol. (London) 227, 553-564

McNeilly, A. S., Legros, J. J. \& Forsling, M. L. (1972) J. Endocrinol. 52, 209-210

Norström, A. \& Sjöstrand, J. (1971a) J. Neurochem. 18, 29-39

Norström, A. \& Sjöstrand, J. (1971b) J. Neurochem. 18, 2007-2016

Norström, A., Sjöstrand, J., Livett, B. G., Uttenthal, L. O. \& Hope, D. B. (1971) Biochem. J. 122, 671-676

Pickering, B. T. \& Jones, C. W. (1971) J. Endocrinol. 49, 93-103

Pickering, B. T., Jones, C. W. \& Burford, G. D. (1971) in Ciba Foundation Study Group no. 39 (Wolstenholme, G. E. W. \& Birch, J., eds.), pp. 58-74, ChurchillLivingstone, London

Pickup, J. C., Johnston, C. I., Nakamura, S., Uttenthal, L. O. \& Hope, D. B. (1973) Biochem. J. 132, 361-371

Rauch, R., Hollenberg, M. D. \& Hope, D. B. (1969) Biochem. J. 115, 473-479

Robinson, A. G., Zimmerman, E. A. \& Franz, A. G. (1971) Metabolism 20, 1148-1155

Sachs, H. (1971) Mem. Soc. Endocrinol. 19, 965-973

Sachs, H. \& Takabatake, Y. (1964) Endocrinology 75, 943-948

Sachs, H., Fawcett, C. P., Takabatake, Y. \& Portanova, R. (1969) Recent Progr. Horm. Res. 25, 447-491

Sachs, H., Saito, S. \& Sunde, D. (1971) Mem. Soc. Endocrinol. 19, 325-336

Uttenthal, L. O. \& Hope, D. B. (1970) Biochem. J. 116, 899-909

Uttenthal, L. O., Livett, B. G. \& Hope, D. B. (1971) Phil. Trans. Roy. Soc. London Ser. B 261, 379-380

van Dyke, H. B., Chow, B. F., Greep, R. O. \& Rothen, A. (1942) J. Pharmacol. Exp. Therapeut. 74, 190-209

Watkins, W. B. (1971) J. Endocrinol. 51, 595-596

Watkins, W. B. (1972a) Biochem. J. 126, 759-760

Watkins, W. B. (1972b) J. Endocrinol. 55, 577-589 